\title{
Mechanical properties and fracture parameters of ultra high performance steel fiber reinforced concrete composites made with extremely low water per binder ratios
}

\author{
Hakar H. Qadir ${ }^{1}$ Rabar H. Faraj ${ }^{1}$ (1) · Aryan Far H. Sherwani ${ }^{2}$ - Barham H. Mohammed ${ }^{1}$ Khaleel H. Younis ${ }^{3,4}$
}

Received: 4 April 2020 / Accepted: 24 August 2020 / Published online: 31 August 2020

(c) Springer Nature Switzerland AG 2020

\begin{abstract}
This study examines the effects of high-volume micro-steel fibers (MSF) content on the mechanical properties, fracture parameters, and ductility of ultra-high performance fiber reinforced concrete (UHPFRCs). The MSFs used in this experiment had an aspect ratio of 37.5 with average length of $6 \mathrm{~mm}$. The investigated parameters include very low water/binder $(\mathrm{w} / \mathrm{b})$ ratio and fiber content. Sixteen UHPFRC mixes were examined, eight mixes were made with $\mathrm{w} / \mathrm{b}$ of 0.12 and eight fiber contents $(0 \%, 1 \%, 1.5 \%, 2 \%, 2.5 \%, 3 \%, 3.5,4 \%)$ while the other eight mixes were made with the same fiber contents but with $\mathrm{w} / \mathrm{b}$ of 0.14 . The UHPFRC mixes were examined for various strengths (compressive, splitting tensile, flexural), elastic modulus, and fracture parameters. The experimental results showed that the mixture with $4 \%$ of MSFs content and $0.12 \mathrm{w} / \mathrm{b}$ ratio exhibited a compressive strength of more than $160 \mathrm{MPa}$, splitting tensile strength higher than $12 \mathrm{MPa}$, and modulus of elasticity greater than $43 \mathrm{GPa}$. Moreover, the results also demonstrated that with increasing MSFs content from 0 to $4 \%$ the load-displacement behavior, ductility, and all other fracture parameters were improved significantly.
\end{abstract}

Keywords Ultra high performance concrete - Micro steel fiber · Water per binder ratio - Mechanical properties . Ductility · Fracture parameters

\section{Introduction}

Ultra-high performance concrete (UHPC) is a special type of concrete developed by selecting the particle sizes and gradation of the constituent materials in micro-scales, targeting the highest possible packing. Unlike high-performance concrete (HPC) and normal strength concrete (NSC) a higher content of cement is used in UHPC [1]. UHPC mixtures have been produced with very low $\mathrm{w} / \mathrm{b}$ ratio due to which, only part of the total cement hydrates and the un-hydrated cement can be replaced with crushed quartz [2-4] UHPC mixes is characterized with low workability because of its very low $\mathrm{w} / \mathrm{b}$ ratio. Using an effective superplasticizer (SP) is one way to enhance the workability of UHPC [5]. Moreover, the silica fume (SF) addition can also improve the workability of UHPC and fill voids between coarser particles due to its finer size and spherical shape, thus improving the strength properties through pozzolanic reactions [6, 7]. Using fine aggregate such as quartz aggregate (instead of coarse aggregates) significantly reduces the maximum paste thickness. Consequently, despite of very brittle failure mode of plain UHPC, the stiffness and strengths of the interfacial transition zone (ITZ) enhanced [8].

Regardless of its types and dimensions, adding fibers will play an important role to enhance resistance to

$\triangle$ Rabar H. Faraj, rabar.faraj@uoh.edu.iq; eng.raberhame@gmail.com | ${ }^{1}$ Civil Engineering Department, University of Halabja, Halabja, Kurdistan Region, Iraq. ${ }^{2}$ Department of Civil Engineering, Faculty of Engineering, Soran University, Soran, Kurdistan Region, Iraq. ${ }^{3}$ Road Construction Department, Erbil Polytechnic University, Erbil, Kurdistan Region, Iraq. ${ }^{4}$ Civil Engineering Department, Tishk International University, Erbil, Kurdistan Region, Iraq. 
cracking, ductility and toughness properties of plain UHPC to form superior quality concrete called UHPFRC. This type of concrete usually incorporates discrete fibers to encourage energy absorption, strain hardening in tension and to avoid sudden failure $[9,10]$. Thus, such improved fracture parameters enable the design of more efficient structures with reduced weight and material consumption.

Numerous researchers have investigated the performance of UHPFRC in order to determine the optimum fiber properties such as; fiber type, volumetric content, distribution homogeneity, length and types of steel fibers [11-13]. Tran et al. [14] investigated the enhancement of fracture parameters of UHPFRC by adding $1-1.5 \%$ fibers. They concluded that smooth fibers exhibited higher fracture strength and specific work-of-fracture at high rates than twisted fibers. Beglarigale and Yazıcı [15] studied the effect of parameters like hooked or smooth end and water/binder ratios on reactive powder concretes. The authors reported, in all curing conditions, type of fibers and decrease in water/binder ratio significantly improved fiber-matrix bond characteristics. Aydın and Baradan [16] investigated drying shrinkage behavior and the mechanical properties of mortars that reinforced with $0.5 \%, 1.0 \%$, $1.5 \%$, and $2.0 \%$ of volume fractions and two different lengths of $6 \mathrm{~mm}$ and $13 \mathrm{~mm}$ of steel fibers. The mechanical properties of mortars enhanced remarkably as the length of fiber increased from 6 to $13 \mathrm{~mm}$. Furthermore, the drying shrinkage of mortars reduced via increasing fiber dosages.

In UHPFRC systems, micro steel fibers (MSF) due to their micro-size have the best consistency with the other concrete cementations since they all in the level of microsize. Thus, it has been found that the MSFs in UHPC in the form of randomly distributed synthetic fibers, will result in enhancing all mechanical properties. For example, Markovic [17] drew the orientation of short MSFs inside concrete (Fig. 1). He found that short steel fibers may still rotate in three directions and the positive influence can be higher than that of long fibers.

Yoo et al. [18] investigated the effect of various fiber contents on the material and interfacial bond properties of UHPFRC, four different volume ratios of MSF $(\mathrm{Vf}=1 \%$ to $4 \%$ by $1 \%$ increment) were used. The MSFs used had an aspect ratio of 65 and a w/b ratio of 0.2. They reported that $3 \%$ MSF by volume showed the best performance in terms of compressive strength, elastic modulus, shrinkage behavior, and interfacial bond strength. They also indicated that higher flexural strength and fracture energy were obtained with higher fiber content.

Chuna and Yoo [19] investigated the effect of different steel fibers on the tensile and pullout behavior of UHPC. The steel fibers utilized in their study had different aspect ratios of 65,80 , and 100 with a constant $\mathrm{w} / \mathrm{b}$ ratio of 0.2 . To illustrate the effect of replacing macro steel fibers with micro steel fibers, five different replacement ratios were employed $(\mathrm{Vf}=0 \%, 0.5 \%, 1 \%, 1.5 \%$ and $2 \%)$. They stated that replacing the macro straight fibers in UHPC with MSFs significantly improved the average bond strength and normalized pullout energy of UHPFRC.

Table 1 shows the geometrical properties of steel fibers, aspect ratio, fiber contents and $\mathrm{w} / \mathrm{b}$ ratio. It also includes the information of current research to illustrate the differences between current investigation and past studies.

It can be seen from Table 1 and the literatures shown above, majority of the researches conducted in the past have focused on UHPFRC containing low volume of MSFs with high aspect ratio. Information regarding the effect of different $\mathrm{w} / \mathrm{b}$ ratios and MSFs with a very low aspect ratio on the performance of UHPFRC is limited. So, the novelty of this research is attributed to the fact the MSF used in this investigation was very short compared to those used in other studies, and two groups of UHPFRC mixtures were produced with two different very low $\mathrm{w} / \mathrm{b}$ ratios. Therefore, this study aims to develop UHPFRC mixes containing relatively high volume of very short MSFs (up to $4 \%$ ) and very low water/binder ratios (0.12 and 0.14 ) along with a new generation of superplasticizer and ultra-fine micro silica particles. Most important mechanical properties such as; flexural strength, modulus of elasticity, tensile strength, compressive strength, load-displacement curve, fracture energy, and characteristic length were studied to evaluate enhancements of strengths, strains, stiffness, toughness, and ductility of UHPFRCs.
Fig. 1 Orientation of micro steel fibers between the mold walls [17] short fibres

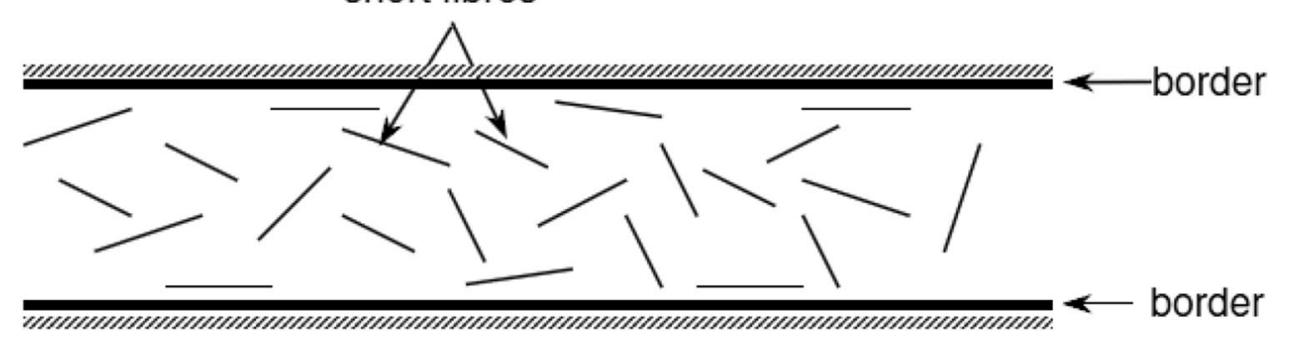


Table 1 Comparison between this investigation and past studies with regard to MSF properties, contents by volume, and w/b ratio

\begin{tabular}{|c|c|c|c|c|c|}
\hline \multirow[t]{2}{*}{ References } & \multirow{2}{*}{$\begin{array}{l}\text { Aspect ratio } \\
\left(L_{f} / d_{f}\right)\end{array}$} & \multicolumn{2}{|c|}{ Geometrical properties } & \multirow[t]{2}{*}{ MSF content by volume } & \multirow[t]{2}{*}{$\mathrm{w} / \mathrm{b}$ ratio } \\
\hline & & Length (mm) & Diameter (mm) & & \\
\hline Yoo et al. [18] & 65.0 & 13.0 & 0.2 & $1 \%, 2 \%, 3 \%$, and $4 \%$ & 0.2 \\
\hline \multirow[t]{4}{*}{ Chuna and Yoo [19] } & 65.0 & 13 & 0.200 & $0 \%, 0.5 \%, 1 \%, 1.5$, and $2 \%$ & 0.2 \\
\hline & 100.0 & 30 & 0.300 & & \\
\hline & 80.0 & 30 & 0.375 & & \\
\hline & 100.0 & 30 & 0.300 & & \\
\hline \multirow[t]{4}{*}{ Yoo et al. [20] } & 65.0 & 13.0 & 0.2 & $2 \%$ & 0.2 \\
\hline & 81.5 & 16.3 & 0.2 & & \\
\hline & 97.5 & 19.5 & 0.2 & & \\
\hline & 100.0 & 30.0 & 0.3 & & \\
\hline Lanwer et al. [21] & 68.4 & 13 & 0.19 & - & 0.2 \\
\hline Wu et al. [22] & 65.0 & 13 & 0.2 & $0 \%, 1 \%, 2 \%$ and $3 \%$ & 0.18 \\
\hline \multirow[t]{3}{*}{ Yoo et al. [23] } & 65.0 & 13.0 & 0.2 & $0.5 \%, 1 \%, 1.5$, and $2 \%$ & 0.2 \\
\hline & 97.5 & 19.5 & 0.2 & & \\
\hline & 100.0 & 30.0 & 0.3 & & \\
\hline Yunsheng et al. [24] & 74 & 13 & 0.175 & $0 \%, 2 \%, 3 \%, 4 \%$ & 0.15 \\
\hline Current investigation & 37.5 & 6.0 & 0.16 & $\begin{array}{l}0 \%, 1 \%, 1.5 \%, 2 \%, 2.5 \%, 3 \%, 3.5, \\
\text { and } 4 \%\end{array}$ & 0.12 and 0.14 \\
\hline
\end{tabular}

Where $L f$ length of fibers, $d f$ diameter

\section{Experimental study}

\subsection{Raw materials}

In this work, Ordinary Portland cement OPC (CEM I 42.5 R) and Silica fume (SF) were used as accompanying cementitious materials. Table 2 shows the chemical composition, physical and mechanical properties of OPC and SF. Commercial quartz sand having specific gravity of 2.65 was used as fine aggregates with two different size fractions in the range of $0-0.4 \mathrm{~mm}$ and $0.6-1.2 \mathrm{~mm}$. Sand with size fraction of 1.2-2.5 $\mathrm{mm}$ was also used instead of coarse aggregate. Type $\mathrm{F}$ polycarboxylate-based superplasticizer was added to all mixes to accomplish the workability limits by ASTM C 494-13 [25]. Also, MSFs were used with different volume fractions as shown in Fig. 2. The physical and mechanical properties as well as the aspect ratios of the fibers are presented in Table 3.

\subsection{Concrete mixture proportioning, casting and sample preparation}

The compositions of UHPFRC used in the present study were recognized by the high volume of binder and MSFs, free of coarse aggregate and extremely low $\mathrm{w} / \mathrm{b}$ ratio $[26,27]$. Two groups with a different $w / b$ of 0.12 and 0.14 each of eight mixes were produced as shown in Table 4. The main reason behind the choice of these ultra-low $\mathrm{w} / \mathrm{b}$ ratios was to investigate the effect of a very low
Table 2 Chemical compositions and physical properties of the ordinary Portland cement and the silica fume

\begin{tabular}{lll}
\hline Parameter & Cement & Silica fume \\
\hline Percent chemical composition & & \\
$\mathrm{Fe}_{2} \mathrm{O}_{3}$ & 2.88 & 1.31 \\
$\mathrm{SO}_{3}$ & 2.63 & 0.41 \\
$\mathrm{~K}_{2} \mathrm{O}$ & 0.88 & 1.52 \\
$\mathrm{CaO}$ & 62.12 & 0.45 \\
$\mathrm{MgO}$ & 1.17 & - \\
$\mathrm{SiO}_{2}$ & 19.69 & 90.36 \\
$\mathrm{Na}_{2} \mathrm{O}$ & 0.17 & 0.45 \\
$\mathrm{Cl}$ & 0.0093 & - \\
$\mathrm{Al}_{2} \mathrm{O}_{3}$ & 5.16 & 0.71 \\
Free CaO & 1.91 & - \\
Physical properties & & \\
Specific surface $\left(m^{2} / \mathrm{kg}\right)$ & 394 & 21,080 \\
Insoluble residue & 0.16 & - \\
Loss on ignition & 2.99 & 3.11 \\
Specific gravity & 3.15 & 2.2 \\
\hline
\end{tabular}

$\mathrm{w} / \mathrm{b}$ ratio compared to those used in the literature. The majority of past investigations were focused on the w/b ratios of about 0.2 as can be seen in Table 1. In both groups, the amount of SF was kept constant to be $15 \%$ by weight of total cementitious materials. MSFs at volume ratios of $0 \%, 1 \%, 1.5 \%, 2 \%, 2.5 \%, 3 \%, 3.5$, and $4 \%$ for each group were added. The mixtures were designated 
Table 3 Properties of micro steel fibers used in this study

\begin{tabular}{llllll}
\hline Fiber type & $\begin{array}{l}\text { Length } \\
(\mathrm{mm})\end{array}$ & $\begin{array}{l}\text { Diameter } \\
(\mathrm{mm})\end{array}$ & $\begin{array}{l}\text { Tensile } \\
\text { strength } \\
(\mathrm{MPa})\end{array}$ & $\begin{array}{l}\text { Aspect } \\
\text { ratio }(\mathrm{L} / \mathrm{d})\end{array}$ & $\begin{array}{l}\text { Density } \\
\left(\mathrm{g} / \mathrm{cm}^{3}\right)\end{array}$ \\
\hline $\begin{array}{c}\text { Straight } \\
\text { micro } \\
\text { steel } \\
\text { fiber }\end{array}$ & 6 & 0.16 & 2250 & 37.5 & 7.17 \\
\hline
\end{tabular}

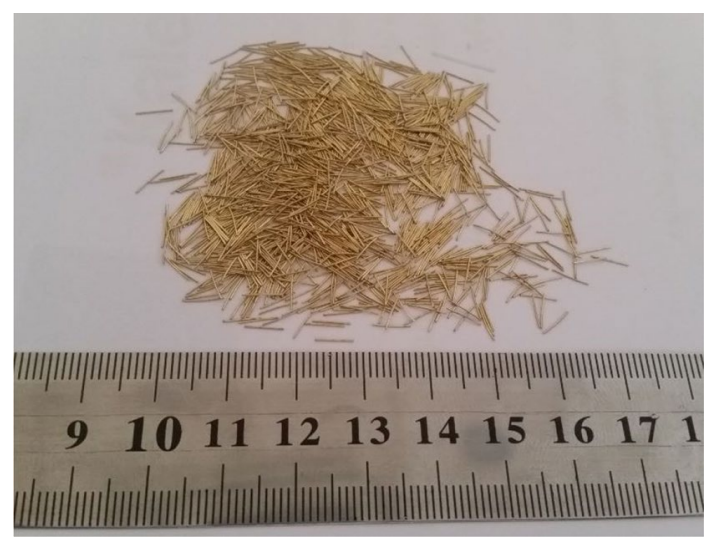

Fig. 2 Views of MSF used in the production of UHPFRC

on two parameters, depended on different volumes of MSF and $w / b$ ratios. For example, $0.12 M S F 1$ indicates the mixture of $0.12 \mathrm{w} / \mathrm{b}$ ratio and $1 \%$ volume of MSF.
For producing UHPC, a high speed, vertical axis mixing machine having a maximum speed of $470 \mathrm{rpm}$ was used. Firstly, binders and quartz were mixed in the machine at low speeds of $100 \mathrm{rpm}$ for $3 \mathrm{~min}$. After that, three-quarters of the water was added to the mixture and remixed for another $4 \mathrm{~min}$ at the same speed. Then the remained water and SP were added to the premixed materials and mixed for $5 \mathrm{~min}$. In the end, MSF was added and mixed for the $2 \mathrm{~min}$ at $100 \mathrm{rpm}$ speed and an extra $2 \mathrm{~min}$ at a speed of $470 \mathrm{rpm}$. The fresh mixtures were then poured into the molds of different sizes; three $150 \mathrm{~mm}$ cubes, six $70 \mathrm{~mm}$ cubes, three $50 \mathrm{~mm}$ cubes, and three prisms of dimension's $70 \times 70 \times 280 \mathrm{~mm}$ to obtain modulus of elasticity, splitting tensile strength, compressive strength, and flexural strength with fracture energy, respectively. Thereafter, the molds were well compacted by using a vibrator machine then covered with polyethylene sheets and left to cure under room temperature. The molds were removed 1 day after casting and cured by standard curing condition until the test date.

\subsection{Testing methods}

The compression test was performed at 7, 14 , and 28 days according to BS 1881-116 [28]. For this test, three cubic specimens of $50 \mathrm{~mm}$ were tested for each mixture, and the average was reported.

Splitting tensile test was conducted with respect to BS 1881-117 [29] on six $70 \mathrm{~mm}$ cubes at 28 days, and the average value was reported.

Table 4 Mix proportions of UHPFRC mixtures for $1 \mathrm{~m}^{3}$ of concrete

\begin{tabular}{|c|c|c|c|c|c|c|c|}
\hline Concrete mixture & $w / b$ & Cement $\left(\mathrm{kg} / \mathrm{m}^{3}\right)$ & $\begin{array}{l}\text { Silica fume } \\
\left(\mathrm{kg} / \mathrm{m}^{3}\right)\end{array}$ & Water $\left(\mathrm{kg} / \mathrm{m}^{3}\right)$ & $\mathrm{SP}\left(\mathrm{kg} / \mathrm{m}^{3}\right)$ & Steel fiber (\%) & $\begin{array}{l}\text { Quartz } \\
\text { aggregate } \\
\left(\mathrm{kg} / \mathrm{m}^{3}\right)\end{array}$ \\
\hline $0.12 \mathrm{MSF} 0$ & 0.12 & 998.8 & 176.25 & 141 & 62.3 & 0 & 1044.6 \\
\hline $0.12 \mathrm{MSF} 1$ & 0.12 & 998.8 & 176.25 & 141 & 64.6 & 1 & 1009.6 \\
\hline $0.12 \mathrm{MSF} 1.5$ & 0.12 & 998.8 & 176.25 & 141 & 67.6 & 1.5 & 989.1 \\
\hline $0.12 \mathrm{MSF} 2$ & 0.12 & 998.8 & 176.25 & 141 & 68.2 & 2 & 974.4 \\
\hline $0.12 \mathrm{MSF} 2.5$ & 0.12 & 998.8 & 176.25 & 141 & 71.1 & 2.5 & 954 \\
\hline $0.12 \mathrm{MSF} 3$ & 0.12 & 998.8 & 176.25 & 141 & 71.7 & 3 & 939.3 \\
\hline $0.12 \mathrm{MSF} 3.5$ & 0.12 & 998.8 & 176.25 & 141 & 72.9 & 3.5 & 923.2 \\
\hline $0.12 \mathrm{MSF} 4$ & 0.12 & 998.8 & 176.25 & 141 & 74 & 4 & 907 \\
\hline $0.14 \mathrm{MSF} 0$ & 0.14 & 998.8 & 176.25 & 164.5 & 47.2 & 0 & 1077.2 \\
\hline $0.14 \mathrm{MSF} 1$ & 0.14 & 998.8 & 176.25 & 164.5 & 49.4 & 1 & 984.7 \\
\hline 0.14 MSF1.5 & 0.14 & 998.8 & 176.25 & 164.5 & 50.2 & 1.5 & 969.6 \\
\hline $0.14 M S F 2$ & 0.14 & 998.8 & 176.25 & 164.5 & 51.9 & 2 & 952.2 \\
\hline 0.14 MSF2.5 & 0.14 & 998.8 & 176.25 & 164.5 & 53.5 & 2.5 & 934.9 \\
\hline $0.14 M S F 3$ & 0.14 & 998.8 & 176.25 & 164.5 & 55.8 & 3 & 916.1 \\
\hline 0.14 MSF3.5 & 0.14 & 998.8 & 176.25 & 164.5 & 57.2 & 3.5 & 899.2 \\
\hline $0.14 \mathrm{MSF} 4$ & 0.14 & 998.8 & 176.25 & 164.5 & 60.1 & 4 & 879 \\
\hline
\end{tabular}




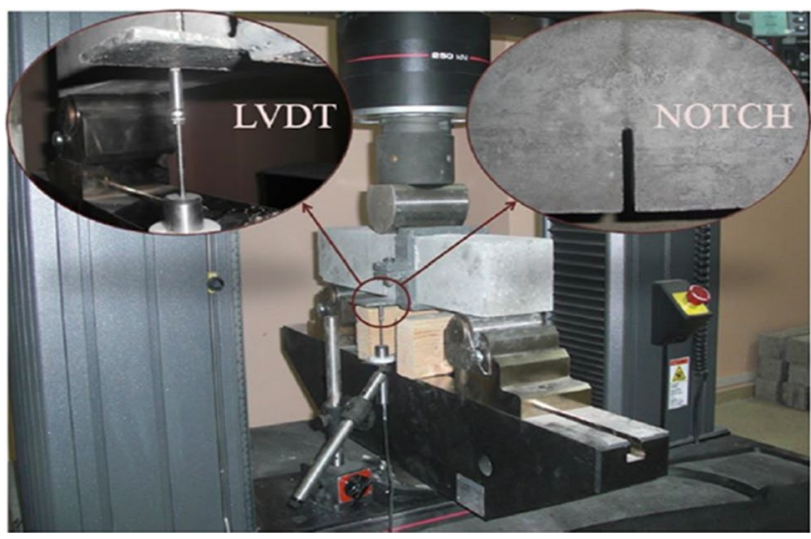

Fig. 3 Photographic view of notched beam specimen

Cubic specimens with dimensions of $150 \mathrm{~mm}$ were used for determining the static modulus of elasticity according to BS EN 1352 [30].

Fracture energy behavior of UHPFRC was investigated according to specifications and recommendations of the RILEM 50-FMC/198 Technical Committee [31]. The test details are shown in Fig. 3. To measure the deflection $(\delta)$ at the mid-span a linear variable displacement transducer (LVDT) was used. This equation was followed to determine fracture energy, given by the Technical Committee RILEM 50-FMC:

$G_{f}=\frac{W 0+m g \delta_{s} b}{B(W-a)}$

$\mathrm{b}=\frac{s}{u}$

where $\mathrm{W}_{0}, \mathrm{~S}, \mathrm{~W}, \mathrm{~B}, \mathrm{a}, \mathrm{U}, \mathrm{m}, \delta_{\mathrm{s}}$, and $\mathrm{g}$ are area under the curve, length, depth, width, depth of the notch, span length, mass, specified beam deflection and acceleration of gravity, respectively.

Equation (3) was implemented to determine the flexural strength, $\mathrm{f}_{\text {flex }}$ by assuming no notch sensitivity [32, 33].

$f_{\text {flex }}=\frac{3 P_{\max } S}{2 B(W-a)^{2}}$

where $P_{\max }$ is the ultimate load.

The brittleness of material in terms of characteristic length was computed using the following equation [34].

$I_{c h}=\frac{E G_{f}}{f_{s t}^{2}}$

where, $\mathrm{f}_{\mathrm{st}}, \mathrm{G}_{\mathrm{F}}$, and $\mathrm{E}$ and are splitting tensile strength, fracture energy and modulus of elasticity respectively.

\section{Results and discussion}

\subsection{Superplasticizer effect on the workability of UHPFRC}

The use of superplasticizer (SP) is critical for compensation of lack of flowability due to the condition of a very low $\mathrm{w} / \mathrm{b}$ ratio for producing high-quality UHPFRCs. In this study, the desired flowability for both groups of 0.12 and $0.14 \mathrm{w} / \mathrm{b}$ was attained as fixed as $12 \pm 1 \mathrm{~cm}$ by adding different amounts of superplasticizer. Irrespective of water contents, it can be noticed from Fig. 4 that an increase in the volume of fibers is accompanied by an increase in the amount of superplasticizers. On the other hand, decreasing $\mathrm{w} / \mathrm{b}$ from 0.14 to 0.12 needed an average increase of $15 \mathrm{~kg} / \mathrm{m}^{3}$ super plasticizer to maintain the same workability. However, when the fiber content increased from 0 to $4 \%$, the demand of SP was increased to 11.7 and $12.9 \mathrm{~kg} /$ $\mathrm{m}^{3}$ for the first and second groups, respectively, in order to keep the flow constant (see Fig. 4 and Table 4).

\section{Compressive strength}

The results of the compressive strength for all UHPCFRCs mixes are shown in Fig. 5a, b. These figures illustrate the effect of the content of MSFs on the compressive strength of UHPC at the ages of 7, 14 and 28 days. At all ages of concrete, the highest compressive strengths were obtained from the mixtures of $0.12 \mathrm{w} / \mathrm{b}$ group with a small difference compared to the group of $0.14 \mathrm{w} / \mathrm{b}$ ratio; this may be due to the small difference in water content between the two groups and the fact that both $\mathrm{w} / \mathrm{b}$ ratios lead to the development hydration products that provide a matrix

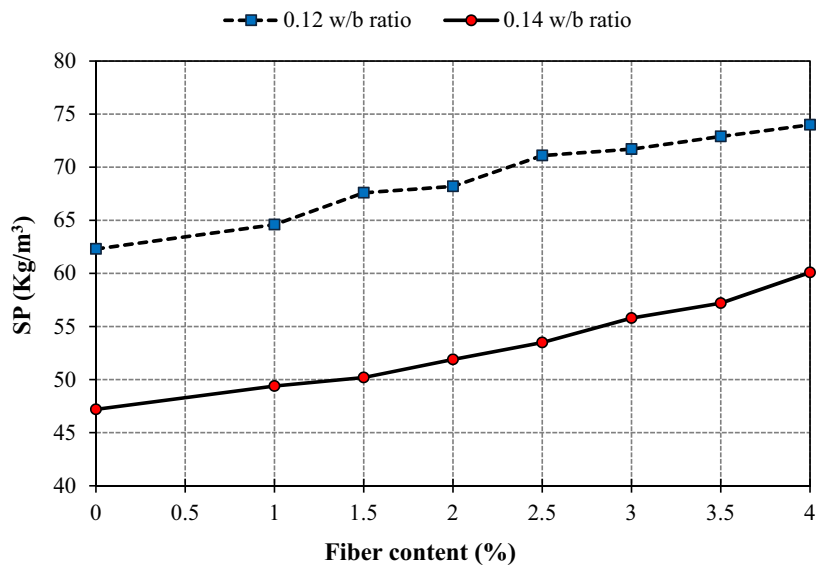

Fig. 4 Superplasticizer amount versus different MSFs content of UHPFRC with $0.12 \mathrm{w} / \mathrm{b}$, and $0.14 \mathrm{w} / \mathrm{b}$ 


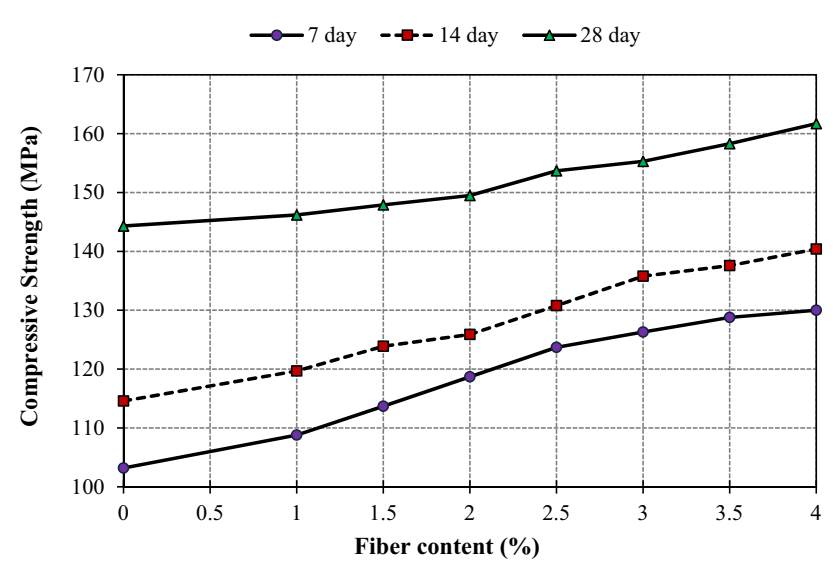

(a)

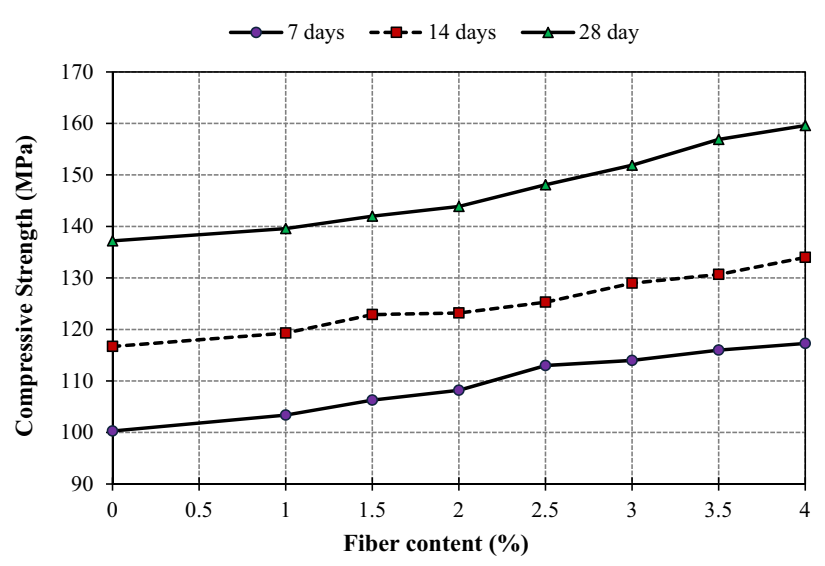

(b)

Fig. 5 Compressive strength of UHPFRC at different ages: a 0.12 $\mathrm{w} / \mathrm{b}$, and b $0.14 \mathrm{w} / \mathrm{b}$

with a skeleton that has a slight difference in strength characteristics. The slight strength reduction observed in the UHPFRCs with increasing $\mathrm{w} / \mathrm{b}$ could be attributed to the formation of further unwanted calcium hydroxide $(\mathrm{CH})$ during the hydration process. Furthermore, the inverse relation between $\mathrm{w} / \mathrm{b}$ and tensile strength was demonstrated also by other researchers $[35,36]$.

Moreover, the results indicated a systematic effect of gradually increasing MSFs content on the growth of compressive strength regulatory. In particular, when the fiber content was increased from 0 to $4 \%$, the improvement in compressive strength at 28 days was as high as $12 \%$, and $16.3 \%$ for the groups of 0.12 , and $0.14 \mathrm{w} / \mathrm{b}$ ratios, correspondingly. Furthermore, with any $0.5 \%$ addition of fibers at 28 days, the average increments of compressive strength were $2.6 \mathrm{MPa}$ for the first and $3.3 \mathrm{MPa}$ for the second group. The reason behind improving UHPFRC strengths is possibly due to the fact that MSFs are much stricter than all surrounding cementitious paste, thus; on loading, the crack is not initiated quickly around the fibers in the mixture, which decelerates the failure of the steel

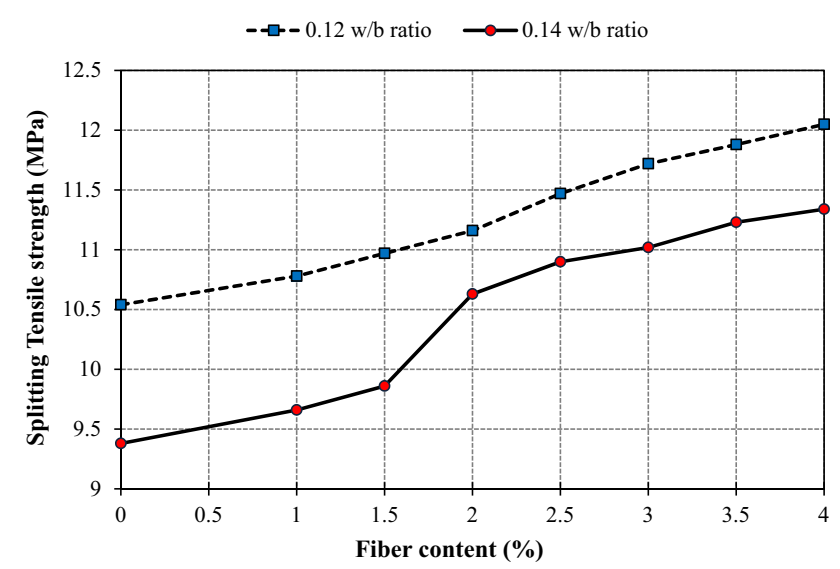

Fig. 6 Splitting tensile strength of UHPFRC versus different volume of MSF content at 28 days

fiber UHPC matrixes. Similar results were observed by Yu et al. [37], in which they found that incorporating $\% 2$ of MSFs content increased the compressive strength by more than $22 \%$ compared to the control mix. The results also demonstrated that the MSF with very low aspect ratio can have a positive influence on the compressive strength improvement, but with a smaller degree of enhancement compared to the MSFs with higher aspect ratios used in the past studies [22].

\subsection{Splitting tensile strength}

The tensile performance of fiber-concrete is expressed into two stages. First; pre-cracking stage, this is usually affected by the elastic shear transfer mechanism between matrix and fiber. Second; the post-cracking stage, this is expressed by the combined effect of matrix tension softening behaviors and fiber bridging [38].

The results of splitting tensile strength for the groups of $w / b$ ratios $(0.12$ and 0.14$)$ containing various dosages of MSF are shown in Fig. 6. The figure also shows the trend of the strength increase with the increase of fiber volume fraction. The reduction in splitting tensile strength observed in the UHPFRCs with increasing $\mathrm{w} / \mathrm{b}$ could be due to the same reasons mentioned in the previous section.

Generally, the utilization of MSFs improves the splitting tensile strength of UHPC. The tensile strength obtained for the control mixtures were $10.54 \mathrm{MPa}$ and $9.38 \mathrm{MPa}$, while adding $1 \%, 1.5 \%, 2 \%, 2.5 \%, 3 \%, 3.5$, and $4 \%$ volume fraction of MSFs prompted an increase in the strength; $2.27 \%$, $4.07 \%, 5.88 \%, 8.82 \%, 11.19 \%, 12.71 \%$ and $14.32 \%$ also $2.98 \%, 5.11 \%, 13.32 \%, 16.2 \%, 17.48,19.72 \%$ and $20.89 \%$ for the first and second groups, respectively. The reason for the increased splitting tensile strength can be attributed to fibers orientation which can play a key role to provide 
sufficient bonds between the aggregate particles and the cement paste that enhances the strength of the concrete. On the other hand, the tensile strength of the concretes contains fibers show failure mechanism unlike that of the plain concrete [39], since a uniform failure state occurs in fiber reinforced concrete, and the specimens did not separate after failing (see Fig. 7).

\subsection{Modulus of elasticity}

The modulus of elasticity of all mixes of UHPC reinforced with different volumes of MSFs tested at 28-day are shown in Fig. 8. Irrespective of the w/b ratio, it can be observed that adding MSFs increases the modulus of elasticity of UHPFRCs. For example, the UHPFRC had an enhancement by $32 \%$ and $50 \%$ at $4 \%$, comparing to their control mixtures, which contains $0 \%$ of MSF for the first and second groups, respectively. The increase in modulus of elasticity of UHPFRCs follows the same trend as for compressive and tensile strength and the reason attributed to the same factors. Irrespective of concrete types, increasing the modulus of elasticity using steel fibers was approved by other researchers $[40,41]$.

\subsection{Flexural strength}

The moduli of rupture or flexural strength values of UHPCs strengthened with different volumes of MSFs are presented in Fig. 9. The results illustrated that with increasing the MSF content from 0 to $4 \%$ the net flexural strength amplified by $41.12 \%$ and $30.33 \%$ for $\mathrm{w} / \mathrm{b}$ ratios of 0.12 and 0.14 , respectively. Improving the flexural strength of concretes can be attributed to the fact that; after cracking of the matrix, the MSFs carry the load until the loss of the bond between the matrix and fibers [42].

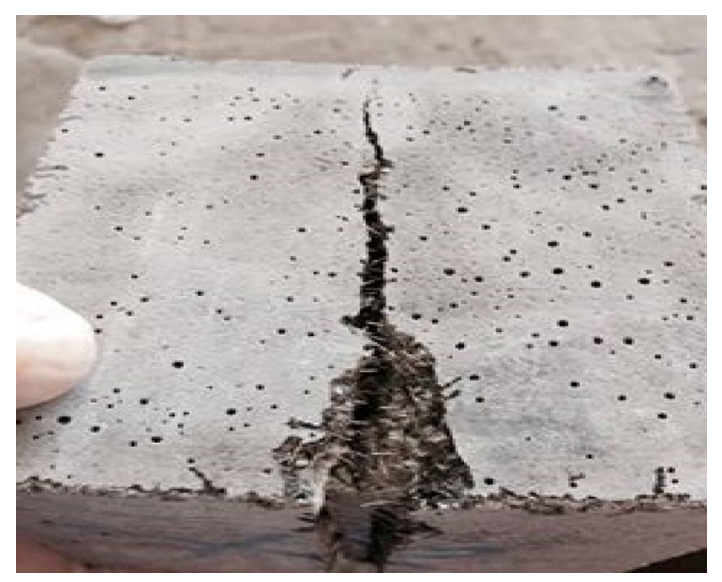

Fig. 7 Failure state in MSF reinforced UHPFRC after splitting tensile strength test

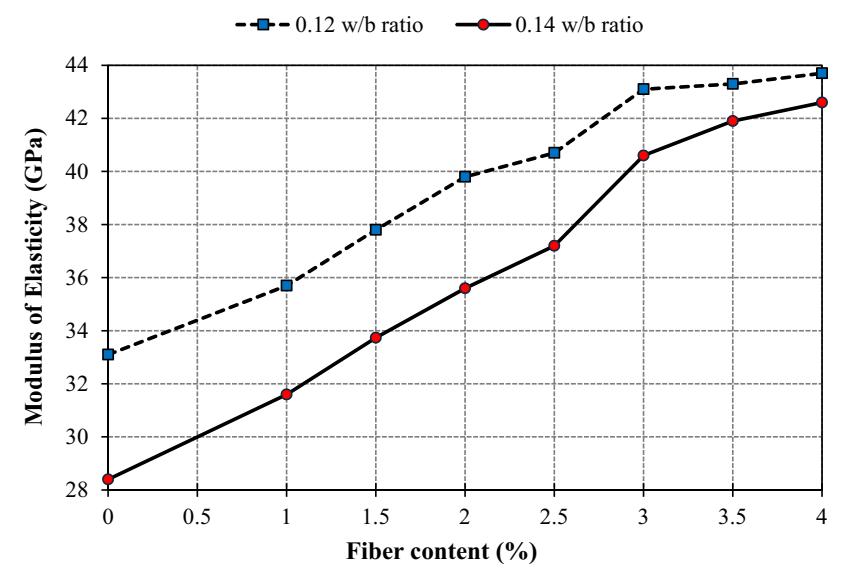

Fig. 8 Modulus of elasticity of UHPFRC versus different volume of MSF content at 28 days

Consequently, because of the efficient crack seizure by the discrete fibers, sudden failure is prevented resulted in the enhancement of the load-carrying capability [43]. It is worth to mention that, while the MSFs with very low aspect ratio was improved the flexural strength of UHPC composite, but it cannot provide a very high flexural strength as obtained from the addition of longer MSFs with higher aspect ratios [24].

On the other hand, the influence of adding fibers is much more than the influence of decreasing water content on the results. For example, the average improvement in the flexural strength with adding $4 \%$ of steel fibers to UHPC is $41.12 \%$ for $0.12 \mathrm{w} / \mathrm{b}$ group, but reducing $\mathrm{w} / \mathrm{b}$ from 0.14 to 0.12 causes a development by $14.23 \%$ for the same mixture containing $4 \%$ of MSF.

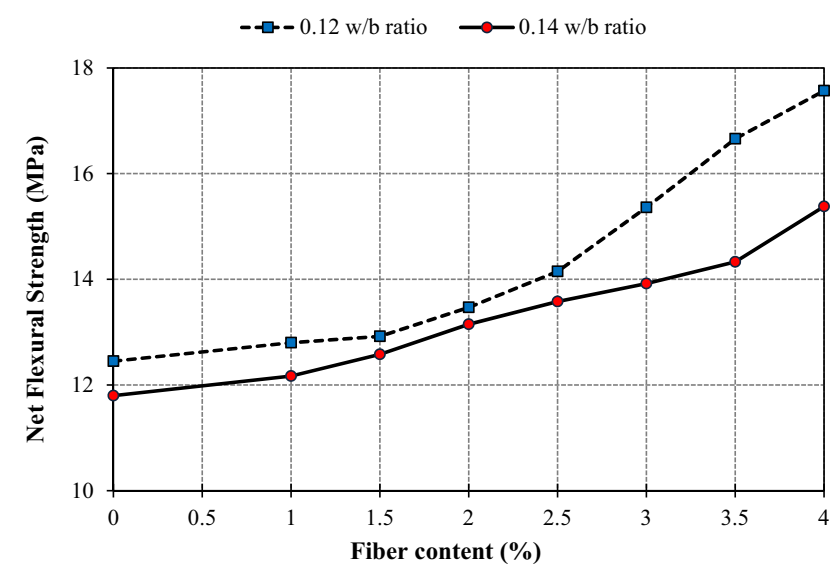

Fig. 9 Effect of different volume of MSF content on net flexural strength of UHPC at 28 days 


\subsection{Load-displacement curves}

The load-displacement curves obtained from notched prismatic UHPFRC specimens subjected to three-point bending test with $0 \%, 1 \%, 1.5 \%, 2 \%, 2.5 \%, 3 \%, 3.5 \%$ and $4 \%$ of MSFs, are presented in Fig. 10a, b for the groups of 0.12 and $0.14 \mathrm{w} / \mathrm{b}$, respectively. Also, Table 5 shows the effect of different volumes of fibers and water content on some properties of UHPFRC such as; area under the load-displacement curve, maximum displacement, and peak load. The UHPC containing 4\% MSF with 0.12 $\mathrm{w} / \mathrm{b}$ had an area under the curve, a maximum deflection, and a peak load of $8424.8 \mathrm{kN} . \mathrm{mm}, 5.4 \mathrm{~mm}$, and $7.2 \mathrm{kN}$, respectively, while these values reduced to $7253.7 \mathrm{kN} . \mathrm{mm}$, $5.2 \mathrm{~mm}$, and $6.3 \mathrm{kN}$ when the $\mathrm{w} / \mathrm{b}$ ratio increased from 0.12 to $0.14 \mathrm{w} / \mathrm{b}$ for the same MSF content. The adverse effects of high $\mathrm{w} / \mathrm{b}$ on the microstructure of concrete were also discussed by other researchers $[44,45]$. The reduction of fracture parameters is due to the fact that any extra water than the demand may play a passive role to restrict improving ITZ, de-bonding between aggregate and binder and obstructing fibers to bridge the micro cracks.

The results also show that with increasing MSFs content the ultimate load was increased significantly, irrespective of the $\mathrm{w} / \mathrm{b}$ ratio. Moreover, as can be seen in Table 5, it is clear that the area under the curve and displacements were remarkably increased with increasing MSFs content. For both $w / b$ ratios, the slope of the ascending part of the curves was not affected significantly for different MSF content; however, the

Table 5 Load-displacement test results

\begin{tabular}{llll}
\hline Concrete mixture & $\begin{array}{l}\text { Area under the } \\
\text { curve }(\mathrm{kN} \mathrm{mm})\end{array}$ & $\begin{array}{l}\text { Maximum } \\
\text { deflection } \\
(\mathrm{mm})\end{array}$ & $\mathrm{P} \max (\mathrm{kN})$ \\
\hline $0.12 \mathrm{MSF} 0$ & 3330.2 & 4.89 & 4.9 \\
0.12 MSF1 & 3479.9 & 5.06 & 5.3 \\
0.12 MSF1.5 & 3597.6 & 5.1 & 5.3 \\
0.12 MSF2 & 4780.9 & 5.15 & 5.6 \\
0.12 MSF2.5 & 4969.2 & 5.2 & 5.8 \\
0.12 MSF3 & 5220.8 & 5.25 & 6.3 \\
0.12 MSF3.5 & 6278.4 & 5.3 & 6.9 \\
0.12 MSF4 & 8424.8 & 5.4 & 7.2 \\
0.14 MSF0 & 2543.5 & 4.58 & 4.6 \\
0.14 MSF1 & 2877.5 & 4.81 & 5.0 \\
0.14 MSF1.5 & 3170.4 & 4.9 & 5.2 \\
0.14 MSF2 & 3270.8 & 4.94 & 5.4 \\
0.14 MSF2.5 & 3853.9 & 5.01 & 5.6 \\
0.14 MSF3 & 4513.4 & 5.06 & 5.7 \\
0.14 MSF3.5 & 5870.4 & 5.1 & 5.9 \\
0.14 MSF4 & 7253.7 & 5.2 & 6.3 \\
\hline
\end{tabular}

descending part for mixtures containing a higher volume of MSFs was remarkably improved. This implies that the utilization of MSFs in UHPC production made the composite more ductile, enhanced toughness and better strain capacity [46]. This can be attributed to the fact that MSFs can efficiently bridge the micro-cracks and increase the capacity of the beam samples. However, as the crack width increases, MSFs become de-active because of pulling out effects [17]. This behavior can be clearly explained by the rapid decrease in the slope of the curves after the specimens reached their maximum load capacity as can be seen in Fig. 10a, b. These results also illustrated that the addition of high volume MSFs with a very low aspect ratio (37.5) can have comparable results with steel fibers of higher aspect ratios (65) regarding the improvement of UHPC to sustain further load even after cracking and increasing the maximum deflection [22].

\subsection{Fracture energy}

The fracture energy $\left(G_{f}\right)$ is defined as the post-crack energy absorption ability of the material, and it represents the energy that the material will absorb during failure or it can be expressed as energy required to opening a unit area of the crack surface $[8,42]$.

The results of the Gf of all mixes are shown in Fig. 11. Both parameters fiber content and $w / b$ ratio clearly affect the Gf of UPFC mixes. It was illustrated in Fig. 11 that the UHPC mix made with $4 \%$ MSFs presented the highest value of the fracture energy, regardless of $w / b$ ratio. For example, adding $4 \%$ of MSF to UHPCs led to an enhancement of fracture energy by $163 \%$, and $195 \%$ for 0.12 and $0.14 \mathrm{w} / \mathrm{b}$ groups, respectively, comparing to control mixtures. These improvements demonstrated that MSFs with very low aspect ratio could also considerably enhance the energy absorption of UHPFRCs especially at higher volume contents. The huge influence of MSF may be related to their superior properties such as aspect ratio and high-tensile strength (see Table 3 ) which made the composite to absorb higher energy before fracture [47]. Prem et al. [47] also reported larger fracture energy of fiber-reinforced UHPCs due to an ability to bridge the cracks.

The rate of development of fracture properties is higher than other mechanical properties such as compressive strength, tensile strength, and elastic modulus. This high improvement may be due to the fact that fracture parameters mainly depend on bond strength and arresting cracks, which they are improved by adding high volume of MSF, but the other properties strongly depended on enhancing ITZ that fibers indirectly contributed to enhance it. 


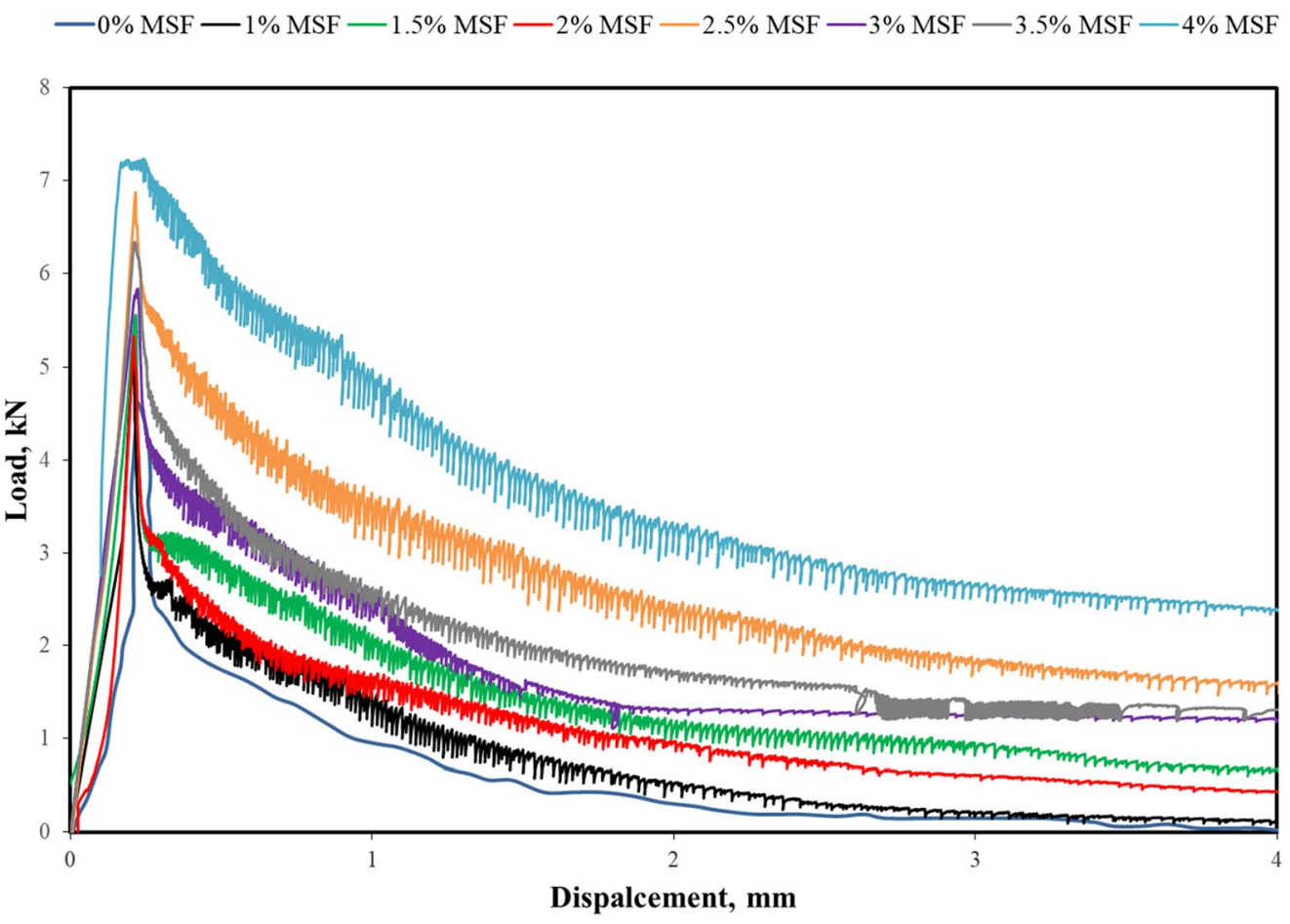

(a)

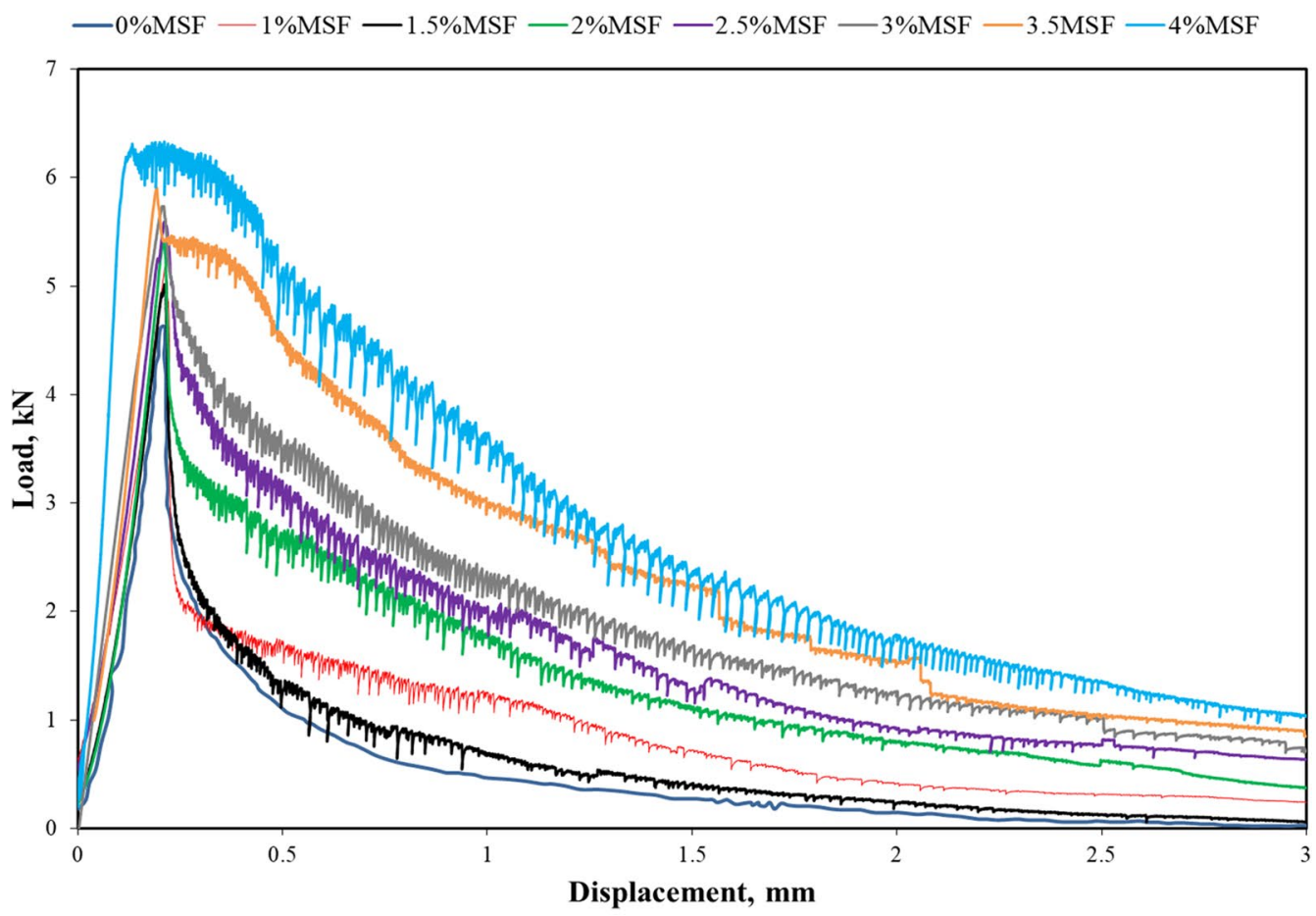

(b)

Fig. 10 Load versus displacement curves of UHPFRC with respect to MSF content: a $0.12 \mathrm{w} / \mathrm{b}, \mathbf{b} 0.14 \mathrm{w} / \mathrm{b}$ group 


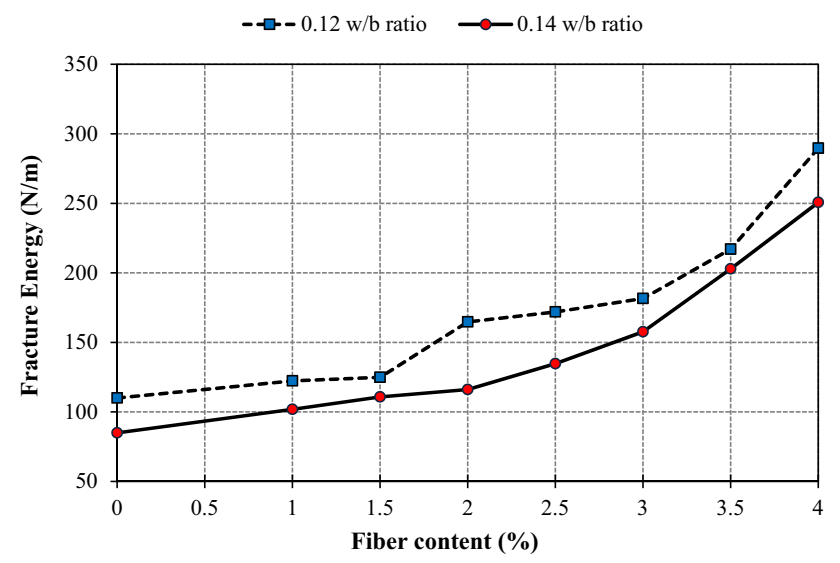

Fig. 11 Fracture energy versus different MSF content of UHPFRC at 28 days

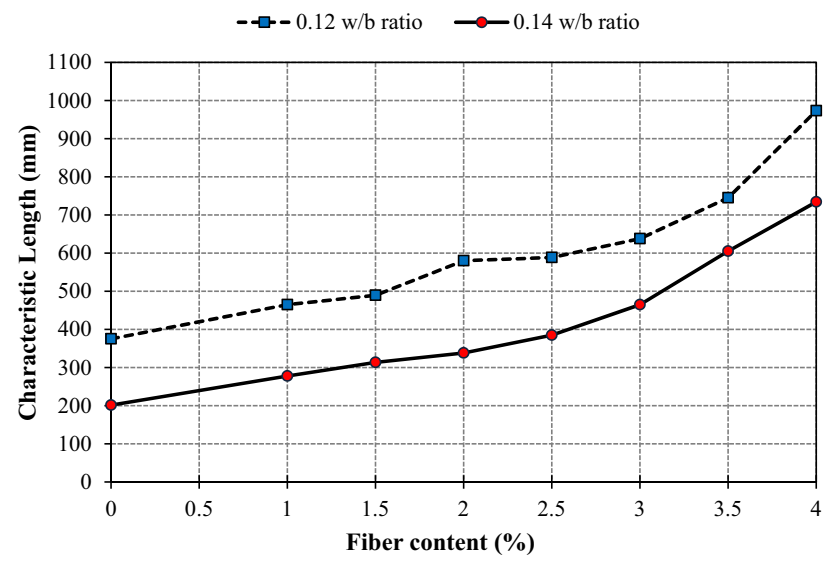

Fig. 12 Characteristic length versus different MSF rate of UHPFRC at 28 days

\subsection{Characteristic length, $I_{c h}$}

The characteristic length $\mathrm{I}_{\mathrm{ch}}$ is a measurement of the brittleness of materials. It mainly depends on the important mechanical characteristics of concrete such as fracture energy, elastic modulus, and tensile strength. The concrete is more ductile when the value of the characteristic length is higher.

The variations in the $\mathrm{I}_{\mathrm{ch}}$ of UHPCs reinforced with different volumes of MSF and two w/b contents ( 0.12 and 0.14 ) are presented in Fig. 12. Comparing to the high increase of ductility by adding a $4 \%$ volume of MSF, the enhancement due to decreasing $\mathrm{w} / \mathrm{b}$ from 0.14 and 0.12 were somewhat small. For example increasing the MSFs content from 0 to $4 \%$ resulted in the improvement of characteristic length by $159 \%$ and $264 \%$ for 0.12 and $0.14 \mathrm{w} / \mathrm{b}$ ratios, respectively, but decreasing the $\mathrm{w} / \mathrm{b}$ ratio from 0.14 to 0.12 resulted in the improvement of characteristic length by an average of $50 \%$ irrespective of MSFs content. The improvement of characteristic length may be attributed to the large number of MSF that dispersed in the matrix at 4\% volume fraction which in turn improved fracture energy (see Fig. 11), leading to enhancement in the characteristic length directly as shown in Eq. 3. Whereas decreasing $\mathrm{w} / \mathrm{b}$ from 0.14 to 0.12 generally enhanced the ITZ by decreasing water content in the matrix rather than a direct effect on fracture properties.

In comparison to the study of Gesoglu et al. [8], there is a huge improvement of the brittleness of UHPC by adding MSF, decreasing $\mathrm{w} / \mathrm{b}$, and increasing binder content. The maximum value that they achieved was nearly $47 \mathrm{~mm}$ for the plain concretes without fibers, with $\mathrm{w} / \mathrm{b}$ of 0.2 and $800 \mathrm{~kg} / \mathrm{m}^{3}$ binder. In the current study, by adding $4 \%$ of MSFs, and using $1175 \mathrm{~kg} / \mathrm{m}^{3}$ of binders, the characteristic lengths of $973.5 \mathrm{~mm}$, and $734.25 \mathrm{~mm}$ were recorded using prisms of the same dimensions of $70 \times 70 \times 280 \mathrm{~mm}$ for 0.12 and $0.14 \mathrm{w} / \mathrm{b}$ groups, respectively. In addition, many other researchers tried to investigate the characteristic length for different concrete types and there was a limited literature regarding UHPC. For example, for the compressive strength range of $40-80 \mathrm{MPa}$, Zhang et al. [48], recorded the characteristic length between $412-235 \mathrm{~mm}$, and Petersson [49] reported values of 200 and $500 \mathrm{~mm}$. Additionally, for self-compacting high-strength concretes containing plastic aggregates, Faraj, et al. [50] found that $\mathrm{I}_{\mathrm{ch}}$ ranged between 85 to $178 \mathrm{~mm}$.

\section{Conclusion}

In this study the influence of very short MSFs with an aspect ratio of 37.5 and two ultralow $\mathrm{w} / \mathrm{b}$ ratios of 0.12 and 0.14 on the mechanical, ductility and fracture properties of UHPFRCs was investigated experimentally. Based on the findings of this investigation the following conclusions can be drawn:

- The incorporation of MSFs has significantly reduced the flowability of UHPFRC. With the increase of fiber content, the flowability gradually decreased especially at $\mathrm{w} / \mathrm{b}$ ratio of 0.12 . Therefore, to maintain the constant workability the amount of superplasticizer should be increased considerably.

- The compressive strength, splitting tensile strength and elastic modulus of UHPFRC remarkably increased with increasing MSFs content regardless of $\mathrm{w} / \mathrm{b}$ ratio and testing age. However, the amount of improvements was relatively smaller compared to the MSFs with higher aspect ratios used in past studies.

- Flexural strength of UHPFRC slightly increased with increasing MSFs content, regardless of $w / b$ ratio. However, increasing the fibers content was more effective 
than decreasing $\mathrm{w} / \mathrm{b}$ ratio on the enhancement of flexural strength.

- There was a remarkable influence of MSFs on the load-displacement curves for both $w / b$ ratios. The area under the curve, displacements and ultimate load were significantly amplified with increasing MSFs content. The utilization of MSF made the composite more ductile, higher toughness and better strain capacity.

- The rates of the development of fracture energy and characteristic length were higher than other mechanical properties such as compressive strength, tensile strength, and elastic modulus. Such improvements may be due to the fact that fracture parameters mainly depend on bond strength and arresting of cracks, which improved by adding high volume of MSFs.

- The overall results demonstrated that the addition of very short MSFs with very low aspect ratio (37.5) can have similar advantages of MSFs with high aspect ratios in improving the mechanical properties of UHPFRC, especially when added at higher volume percentages.

As mentioned above, MSFs with a very low aspect ratio (37.5) can remarkably improve all mechanical, fracture and ductility behavior of UHPFRC. However, other important properties such as microstructure, shrinkage and durability related properties need to be considered in further investigations.

\section{Compliance with ethical standards}

Conflict of interest The authors declare that they have no conflict of interest.

\section{References}

1. Schmidt M, Fehling E (2005) Ultra-high-performance concrete: research, development and application in Europe. ACI Spec Publ 1(228):51-78

2. Richard P, Cheyrezy M (1995) Composition of reactive powder concretes. Cem Concr Res 25(7):1501-1511

3. Soutsos MN, Millard SG, Karaiskos K (2005) Mix design, mechanical properties, and impact resistance of reactive powder concrete (RPC). In: International RILEM workshop on high performance fiber reinforced cementitious composites (HPFRCC) in structural applications, pp 549-560

4. Yazıcı H (2007) The effect of curing conditions on compressive strength of ultra high strength concrete with high volume mineral admixtures. Build Environ 42(5):2083-2089

5. Tue NV, Ma J, Orgass M (2008) Influence of addition method of superplasticizer on the properties of fresh UHPC. In: Proceedings of second international symposium on ultra high performance concrete, University of Kassel, Germany 2008, pp 93-100

6. Faraj RH, Sherwani AFH, Jafer LH, Ibrahim DF (2020) Rheological behavior and fresh properties of self-compacting high strength concrete containing recycled PP particles with fly ash and silica fume blended. J Build Eng. https://doi.org/10.1016/j. jobe.2020.101667

7. Neves RD, Fernandes de Almeida JC (2005) Compressive behaviour of steel fibre reinforced concrete. Struct Concr 6(1):1-8

8. Gesoglu M, Güneyisi E, Asaad DS, Muhyaddin GF (2016) Properties of low binder ultra-high performance cementitious composites: comparison of nanosilica and microsilica. Constr Build Mater 15(102):706-713

9. Yu R, Spiesz P, Brouwers HJ (2016) Energy absorption capacity of a sustainable ultra-high performance fibre reinforced concrete (UHPFRC) in quasi-static mode and under high velocity projectile impact. Cement Concr Compos 30(68):109-122

10. Yoo DY, Banthia N, Yoon YS (2016) Flexural behavior of ultrahigh-performance fiber-reinforced concrete beams reinforced with GFRP and steel rebars. Eng Struct 15(111):246-262

11. Park SH, Ryu GS, Koh KT, Kim DJ (2014) Effect of shrinkage reducing agent on pullout resistance of high-strength steel fibers embedded in ultra-high-performance concrete. Cement Concr Compos 31(49):59-69

12. Kang ST, Choi Jl, Koh KT, Lee KS, Lee BY (2016) Hybrid effects of steel fiber and microfiber on the tensile behavior of ultra-high performance concrete. Compos Struct 10(145):37-42

13. Qi J, Wu Z, Ma ZJ, Wang J (2018) Pullout behavior of straight and hooked-end steel fibers in UHPC matrix with various embedded angles. Constr Build Mater 191:764-774

14. Tran NT, Tran TK, Jeon JK, Park JK, Kim DJ (2016) Fracture energy of ultra-high-performance fiber-reinforced concrete at high strain rates. Cem Concr Res 31(79):169-184

15. Beglarigale A, Yazıc H (2015) Pull-out behavior of steel fiber embedded in flowable RPC and ordinary mortar. Constr Build Mater 30(75):255-265

16. Aydın S, Baradan B (2013) The effect of fiber properties on high performance alkali-activated slag/silica fume mortars. Compos B Eng 45(1):63-69

17. Markovic I (2006) High-performance hybrid-fibre concretedevelopment and utilisation. Technische Universitat Delft, Ph.D. thesis; 2006

18. Yoo D-Y, Shin H-O, Yang J-M, Yoon Y-S (2014) Material and bond properties of ultra high performance fiber reinforced concrete with micro steel fibers. Compos B Eng 58:122-133. https://doi. org/10.1016/j.compositesb.2013.10.081

19. Chun B, Yoo D-Y (2018) Hybrid effect of macro and micro steel fibers on the pullout and tensile behaviors of ultra-high-performance concrete. Compos B. https://doi.org/10.1016/j.compo sitesb.2018.11.026

20. Yoo D-Y, Kang S-T, Yoon Y-S (2014) Effect of fiber length and placement method on flexural behavior, tension-softening curve, and fiber distribution characteristics of UHPFRC. Constr Build Mater 64:67-81. https://doi.org/10.1016/j.conbuildma t.2014.04.007

21. Lanwer J-P, Oettel V, Empelmann M, Höper S, Kowalsky U, Dinkler D (2019) Bond behavior of micro steel fibers embedded in ultrahigh performance concrete subjected to monotonic and cyclic loading. Struct Concr 20(4):1243-1253. https://doi.org/10.1002/ suco. 201900030

22. Wu Z, Shi C, He W, Linmei Wu (2016) Effects of steel fiber content and shape on mechanical properties of ultra high performance concrete. Constr Build Mater 103:8-14. https://doi.org/10.1016/j. conbuildmat.2015.11.028

23. Yoo D-Y, Kim S, Park G-J, Park J-J, Kim S-W (2017) Effects of fiber shape, aspect ratio, and volume fraction on flexural behavior of ultra-high-performance fiber-reinforced cement composites. Compos Struct 174:375-388. https://doi.org/10.1016/j.comps truct.2017.04.069

24. Yunsheng Z, Wei S, Sifeng L, Chujie J, Jianzhong L (2008) Preparation of $\mathrm{C} 200$ green reactive powder concrete and its 
static-dynamic behaviors. Cem Concr Compos 30(9):831-838. https://doi.org/10.1016/j.cemconcomp.2008.06.008

25. ASTM C494, C494M-13 (2013) Standard specification for chemical admixtures for concrete. ASTM International, West Conshohocken

26. Corinaldesi V, Moriconi G (2012) Mechanical and thermal evaluation of ultra high performance fiber reinforced concretes for engineering applications. Constr Build Mater 26(1):289-294

27. Yazıcı H, Yardımcı MY, Yiğiter H, Aydın S, Türkel S (2010) Mechanical properties of reactive powder concrete containing high volumes of ground granulated blast furnace slag. Cem Concr Compos 32(8):639-648

28. BS 1881: Part 116 (1983) Testing concrete. Method for determination of compressive strength of concrete cubes. British Standard Institutions, UK

29. BS 1881: Part 117 (1983). Testing concrete. Method for the determination of tensile splitting strength, British Standard Institutions, UK

30. BS EN 1352 (1997) Determination of static modulus of elasticity under compression of autoclaved aerated concrete or lightweight aggregate concrete with open structure. British Standard Institutions, UK

31. RILEM 50-FMC (1985) Committee of fracture mechanics of concrete, Determination of fracture energy of mortar and concrete by means of three-point bend tests on notched beams. Mater Struct 18(106):285-290

32. Ravindra KD, Henderson NA (1999) Specialist techniques and materials for concrete production. Thomas Telford Publishing, Thomas Telford Ltd, London

33. Akcay B, Agar-Ozbek AS, Bayramov F, Atahan HN, Sengul C, Tasdemir MA (2012) Interpretation of aggregate volume fraction effects on fracture behavior of concrete. Constr Build Mater 28(1):437-443

34. Hillerborg A (1985) The theoretical basis of a method to determinate the fracture energy G F of concrete. Mater Struct 18(4):291-296

35. Sekhar NS, Raghunath PN (2014) Influence of water binder ratio on high performance concrete. Open Constr Build Technol J 8:18-21

36. Šerelis E, Deligia M, Vaitkevičius V, Kerševičius V (2015) Influence of water to cement ratio with different amount of binder on properties of ultra-high performance concrete. J Sustain Archit Civ Eng 10(1):78-86

37. Yu R, Spiesz P, Brouwers HJ (2014) Static properties and impact resistance of a green ultra-high performance hybrid fibre reinforced concrete (UHPHFRC): experiments and modeling. Constr Build Mater 15(68):158-171

38. Kang ST, Kim JK (2012) Investigation on the flexural behavior of UHPCC considering the effect of fiber orientation distribution. Constr Build Mater 28(1):57-65
39. Gesoglu M, Güneyisi E, Hansu O, İpek S, Asaad DS (2015) Influence of waste rubber utilization on the fracture and steel-concrete bond strength properties of concrete. Constr Build Mater 30(101):1113-1121

40. Kayali O, Haque MN, Zhu B (2003) Some characteristics of high strength fiber reinforced lightweight aggregate concrete. Cement Concr Compos 25(2):207-213

41. Bilodeau A, Kodur VK, Hoff GC (2004) Optimization of the type and amount of polypropylene fibres for preventing the spalling of lightweight concrete subjected to hydrocarbon fire. Cement Concr Compos 26(2):163-174

42. Gesoğlu M, Güneyisi E, Muhyaddin GF, Asaad DS, Yılmaz ME (2016) Strain hardening ultra-high performance fiber reinforced cementitious composites: Effect of fiber type and concentration. Compos B. https://doi.org/10.1016/j.compositesb.2016.08.004

43. Hassanpour M, Shafigh P, Mahmud HB (2012) Lightweight aggregate concrete fiber reinforcement-a review. Constr Build Mater 31(37):452-461

44. Wang D, Shi C, Wu Z, Xiao J, Huang Z, Fang Z (2015) A review on ultra high performance concrete: Part II. Hydration, microstructure and properties. Constr Build Mater 96:368-77

45. Rong ZD, Sun W, Xiao HJ, Wang W (2014) Effect of silica fume and fly ash on hydration and microstructure evolution of cement based composites at low water-binder ratios. Constr Build Mater 31(51):446-450

46. Wu Z, Khayat KH, Shi C (2018) How do fiber shape and matrix composition affect fiber pullout behavior and flexural properties of UHPC? Cem Concr Compos 90:193-201

47. Prem PR, Bharatkumar BH, lyer Nagesh R (2012) Mechanical properties of ultra high performance concrete. World Acad Sci Eng Technol 6:08-23

48. Zhang J, Leung CK, Xu S (2010) Evaluation of fracture parameters of concrete from bending test using inverse analysis approach. Mater Struct 43(6):857-874

49. Petersson PE (1980) Fracture energy of concrete: practical performance and experimental results. Cem Concr Res 10(1):91-101

50. Faraj RH, Sherwani AFH, Daraei A (2019) Mechanical, fracture and durability properties of self-compacting high strength concrete containing recycled polypropylene plastic particles. J Build Eng 25:100808. https://doi.org/10.1016/j.jobe.2019.100808

Publisher's Note Springer Nature remains neutral with regard to jurisdictional claims in published maps and institutional affiliations. 